\title{
Estoque de carbono orgânico no solo afetado por adubação orgânica e sistemas de culturas no Sul do Brasil
}

\section{Organic carbon stock in soil affected by organic fertilization and cropping systems in southern Brazil}

\author{
Fábio Steiner ${ }^{*}$; Laércio Augusto Pivetta ${ }^{1}$; Tiago Zoz ${ }^{1}$; Artur Soares Pinto Junior ${ }^{2}$
}

\section{Resumo}

O carbono orgânico é um dos principais componentes da matéria orgânica do solo e o seu estoque é influenciado pelo sistema de manejo adotado. Este estudo teve como objetivo verificar os efeitos de sistemas de culturas e fontes de nutrientes (mineral e orgânico) nos teores e no estoque de carbono orgânico do solo em sistema de plantio direto. O experimento foi conduzido em Mercedes, PR, em um Nitossolo Vermelho, de outubro de 2007 a setembro de 2009. Os tratamentos foram constituídos por quatro sistemas de sucessão de culturas: (1) soja/trigo/milho/trigo, (2) soja/aveia $\mathrm{preta} / \mathrm{milho} /$ aveia preta, (3) soja/nabo forrageiro/milho/nabo forrageiro e (4) soja/ervilha comum/milho/ervilhaca comum e por duas fontes de nutrientes (mineral e orgânica), dispostos em um delineamento de blocos ao acaso em parcelas subdivididas com quatro repetições. Amostras de solos foram coletas nas camadas de $0,0-0,05,0,05-0,10,0,10-0,20$ e $0,20-0,40 \mathrm{~m}$ de profundidade, no primeiro e no segundo anos de experimento. Os diferentes sistemas de sucessão de culturas não afetaram os teores e os estoques de carbono orgânico do solo nos dois primeiros anos de adoção dos sistemas. A adubação orgânica com esterco animal proporcionou aumento no estoque de carbono orgânico do solo, com um aporte anual de C, na camada de 0,0-0,20 m, de 1,15 $\mathrm{Mg} \mathrm{ha}^{-1}$ ano $^{-1}$. Sistemas de culturas adubados com fertilizante mineral proporcionam as maiores perdas de carbono orgânico no solo, resultando em balanço negativo de $\mathrm{C}$ no solo.

Palavras-chave: Manejo do solo, plantas de cobertura, matéria orgânica, adubação orgânica, plantio direto

\begin{abstract}
Organic carbon is a major component of soil organic matter and its stock is influenced by the management system adopted. This study aimed to examine the effects of cropping systems and nutrient sources (mineral and organic) on the concentrations and storage of soil organic carbon in no-tillage system. The experiment was carried out in Mercedes, Parana, Brazil, in an Nitossolo Vermelho (Alfisol) from October 2007 to September 2009. The treatments consisted of four crop succession systems: (1) soybean/wheat/corn/wheat; (2) soybean/black oat/ corn/black oat, (3) soybean/radish/corn/radish and (4) soybean/common vetch/corn/common vetch and by two sources of nutrients (mineral and organic), arranged in a to split plot randomized block design with four replications. Soil samples were collected in layers of $0.0-0.05,0.05-0.10,0.10-0.20$ and 0.20 to $0.40 \mathrm{~m}$ deep in the first and the second years of cultivation. Different cropping systems does not affect the content and the stock of soil organic carbon
\end{abstract}

\footnotetext{
${ }^{1}$ Programa de Pós-Graduação em Agronomia/Agricultura. Faculdade de Ciências Agronômicas, FCA. Universidade Estadual Paulista Júlio de Mesquita Filho, UNESP, Botucatu, SP. E-mail: fsteiner@fca.unesp.br; tiagozoz@fca.unesp.br; laerciopivetta@ fca.unesp.br

${ }^{2}$ Programa de Pós-Graduação em Agronomia, Universidade Estadual do Oeste do Paraná, UNIOESTE, Marechal Cândido Rondon, PR. E-mail: arturbio@hotmail.com

* Autor para correspondência
} 
in the first two years of adoption of the systems. The organic fertilization with manure increased soil organic carbon stock, with an annual contribution of C, layer 0.0 to $0.20 \mathrm{~m}, 1.15 \mathrm{Mg} \mathrm{ha}^{-1} \mathrm{yr}^{-1}$. Cropping systems fertilized with mineral fertilizers provide the greatest losses of soil organic carbon, resulting in negative balance of $\mathrm{C}$ in soil.

Key words: Soil management, cover crops, organic matter, organic fertilization, no-till

\section{Introdução}

A matéria orgânica do solo (MOS) constitui o maior reservatório de carbono (C) do solo. O estoque de carbono orgânico do solo pode ser alterado com maior ou menor intensidade, dependendo do sistema agrícola instalado, sendo um dos atributos mais sensíveis às transformações desencadeadas pelo manejo. Práticas de manejo inadequadas podem levar a um rápido declínio do estoque de carbono orgânico do solo, contribuindo para o aumento das emissões de dióxido de carbono $\left(\mathrm{CO}_{2}\right)$ à atmosfera (FREIXO et al., 2002). Por outro lado, sistemas de manejo que aumentem a adição de resíduos vegetais e a retenção de $\mathrm{C}$ no solo representam alternativas importantes para aumentar a capacidade de dreno de $\mathrm{C}-\mathrm{CO}_{2}$ atmosférico e mitigação do aquecimento global (AMADO et al., 2001; BAYER et al., 2006; CARNEIRO et al., 2009).

O sistema de plantio direto é uma das mais efetivas práticas de conservação do solo, contribuindo para a redução das perdas de solo e de C orgânico (SCHICK et al., 2000; SANTOS et al., 2007), principalmente devido à manutenção dos resíduos vegetais na superfície do solo e proteção física da matéria orgânica em agregados (SIX et al., 2004; CALEGARI et al., 2006). Porém, a eficiência desse sistema em manter e/ou até mesmo aumentar o estoque de C orgânico do solo está relacionada ao manejo de culturas utilizadas (LOVATO et al., 2004; BAYER et al., 2006; CALEGARI et al., 2006). Em experimento de longa duração (18 anos) conduzido no Rio Grande do Sul, Costa et al. (2008) verificaram que o plantio direto associado a sistemas de cultura com alta adição de resíduos vegetais ricos em $\mathrm{C}$ e nitrogênio $(\mathrm{N})$ resultou no aumento do estoque de $\mathrm{C}$ orgânico no solo.
A região Oeste do Estado do Paraná caracterizase predominantemente por pequenas e médias propriedades rurais, nas quais os produtores têm suas atividades baseadas na produção de grãos e na produção animal. Essa característica leva a região a produzir quantidade considerável de esterco animal (suíno, bovino e avícola), com potencial para produção de adubos orgânicos. A adubação orgânica possui inúmeras vantagens, como o aproveitamento racional de todos os recursos disponíveis dentro da propriedade rural, estabelecendo-se o princípio de que o resíduo de um sistema pode constituir-se em um insumo potencial para outro sistema; o aumento da estabilidade dos sistemas de produção existentes, com o investimento em novos componentes tecnológicos; a maximização da eficiência dos sistemas de produção existentes, reduzindo custos e melhorando a produtividade de maneira sustentável social, econômica e ambientalmente (KONZEN; ALVARENGA, 2005).

A aplicação de esterco animal constitui-se em uma excelente fonte de nutrientes as plantas e quando manejada adequadamente, pode suprir parcial ou totalmente o fertilizante mineral (MATSI; LITHOURGIDIS; GAGIANAS, 2003; PAULETTI et al., 2008; CASTOLDI et al., 2011). Além de fornecer nutrientes, a aplicação de esterco animal diminui a densidade e a resistência do solo à penetração, aumenta a capacidade de retenção de água, aumenta o conteúdo de C orgânico e a atividade microbiana, dentre outros (MOSADDEGHI; MAHBOUBI; SAFADOUST, 2009; COSTA et al., 2011a), melhorando as propriedades físicas do solo. No entanto, a adoção do sistema de plantio direto trouxe alterações importantes no manejo da utilização do esterco animal. Estes, que antes eram aplicados sobre a superfície e imediatamente 
incorporados ao solo, atualmente são aplicados sobre a camada de palha existente no plantio direto e deixados na superfície do solo. Segundo Scherer e Nesi (2009), essa forma de aplicação de esterco impede ou retarda o contato do adubo com o solo e microorganismos, com possíveis reflexos na mineralização dos compostos orgânicos, na dinâmica dos nutrientes e no estoque de C orgânico no solo.

Até o momento, poucos foram os estudos realizados no Estado do Paraná, que abordaram o efeito de culturas de cobertura associado à adubação orgânica sobre o estoque de carbono orgânico do solo. Em Nitossolo Vermelho em Chapecó, Santa Catarina, Andreola et al. (2000) verificaram que a utilização de plantas de cobertura de inverno [Avena strigosa (aveia preta) + Raphanus sativus (nabo forrageiro)], quando associadas à adubação orgânica, aumentaram o teor de carbono orgânico no solo, enquanto os adubos organomineral e mineral mostraram tendência à redução.
Este estudo teve como objetivo verificar os efeitos de sistemas de culturas e fontes de nutrientes (mineral e orgânico) nos teores e no estoque de carbono orgânico do solo em sistema de plantio direto.

\section{Material e Métodos}

$\mathrm{O}$ experimento foi realizado em Mercedes, PR (latitude: $24^{\circ} 45^{\prime} \mathrm{S}$, longitude: $54^{\circ} 03^{\prime} \mathrm{W}$ e altitude: $380 \mathrm{~m}$ ), em um Nitossolo Vermelho de textura argilosa, com relevo plano a suave ondulado. O clima da região, segundo classificação de Köppen, é do tipo Cfa, caracterizado como subtropical úmido mesotérmico, com verões quentes, invernos com geadas pouco frequentes, sem estação seca definida, com precipitação anual de $1.500 \mathrm{~mm}$ e temperatura média anual de $21,4{ }^{\circ} \mathrm{C}$. Os dados climáticos referentes ao período de condução do experimento estão apresentados na Figura 1.

Figura 1. Precipitação mensal acumulada $(\mathrm{mm})$ e temperatura média mensal $\left({ }^{\circ} \mathrm{C}\right)$ durante o experimento. Ss implantação do experimento com a semeadura da soja, $1^{\mathrm{a}} \mathrm{e} 2^{\mathrm{a}}$ - primeira e segunda amostragens de solo, respectivamente.

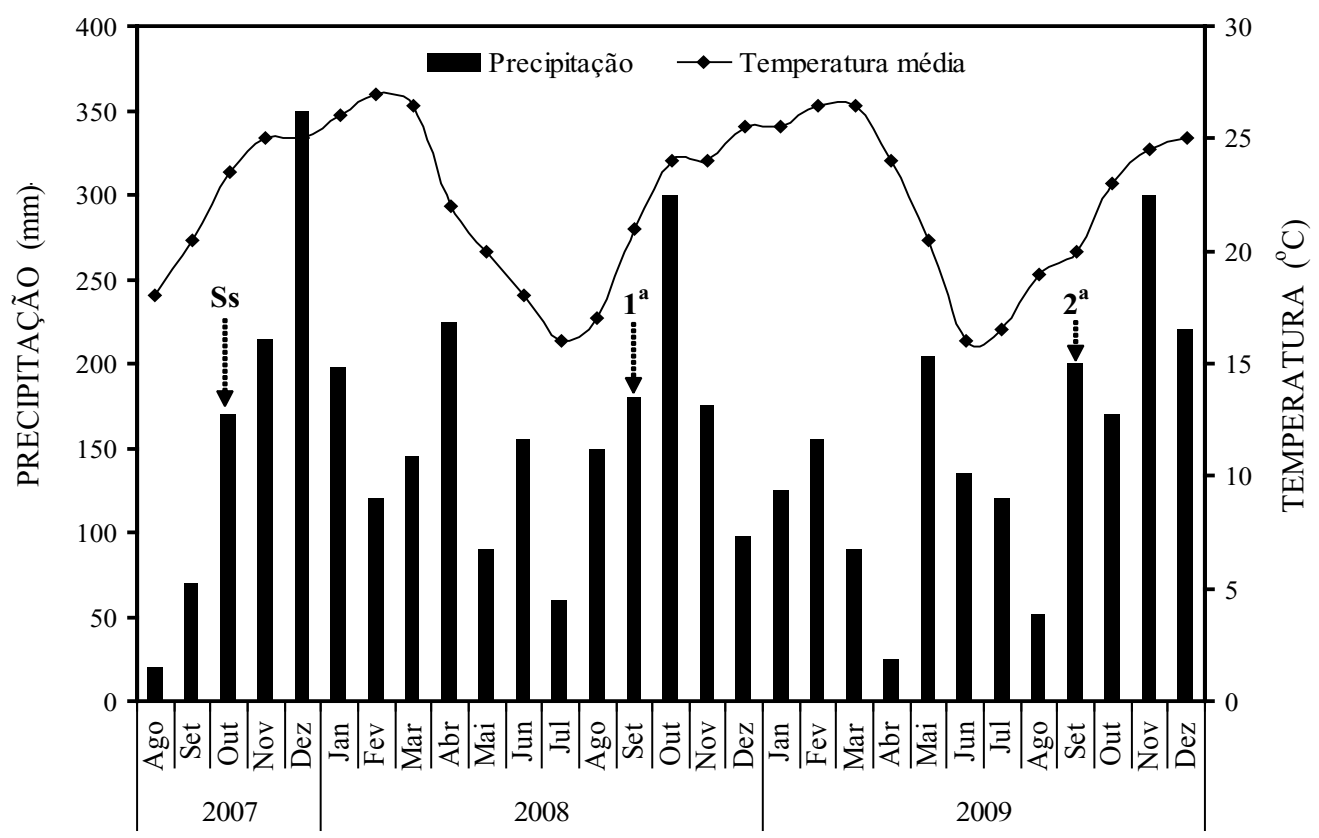

Fonte: Elaboração dos autores. 
A área experimental havia sido anteriormente cultivada com milho/soja e aveia/milheto em sistema de semeadura direta durante doze anos. Antes da instalação do experimento, coletaram-se amostras de solo nas camadas de $0,0-0,05 ; 0,05$ 0,$10 ; 0,10-0,20$ e $0,20-0,40 \mathrm{~m}$ e os resultados da análise química são apresentados na Tabela 1.

O delineamento experimental empregado foi o de blocos ao acaso em parcelas subdivididas, com quatro repetições. Nas parcelas principais foram estabelecidos os quatro sistemas de sucessão de culturas: (1) soja/trigo/milho/trigo, (2) soja/aveia preta/milho/aveia preta, (3) soja/nabo forrageiro/ milho/nabo forrageiro e (4) soja/ervilha comum/ milho/ervilhaca comum; nas subparcelas foram utilizadas duas fontes de nutrientes (mineral e orgânica). Cada unidade experimental foi constituída de 8,0 m de comprimento e $6,0 \mathrm{~m}$ de largura $\left(48 \mathrm{~m}^{2}\right)$. A adubação mineral e orgânica foi realizada segundo a necessidade da cultura (RAIJ et al., 1997), mediante análise do solo. A quantidade de esterco animal aplicado foi calculada, para cada cultura, de acordo com os teores de nutrientes do esterco utilizado e dos respectivos índices de eficiência de liberação no primeiro cultivo. Os índices de eficiência de liberação dos nutrientes no solo utilizados foram os seguintes: $\mathrm{N}=0,8 ; \mathrm{P}=$ 0,8 e $\mathrm{K}=1,0$ para o dejeto líquido de suínos e $\mathrm{N}=$ 0,$5 ; \mathrm{P}=0,7$ e $\mathrm{K}=1,0$ para a cama-de-aviário, como proposto por Konzen e Alvarenga (2005).

Tabela 1. Características químicas e densidade do solo, nas camadas de $0,0-0,05 ; 0,05-0,10 ; 0,10-0,20$ e $0,20-0,40$ m de profundidade.

\begin{tabular}{ccccccccccc}
\hline Profundidade & $\mathrm{pH}$ & $\mathrm{P}$ & $\mathrm{CO}$ & $\mathrm{H}+\mathrm{Al}$ & $\mathrm{K}^{+}$ & $\mathrm{Ca}^{2+}$ & $\mathrm{Mg}^{2+}$ & $\mathrm{CTC}$ & $\mathrm{V}$ & $\mathrm{Ds}$ \\
\hline$(\mathrm{m})$ & & $\mathrm{mg} \mathrm{dm}^{-3}$ & $\mathrm{~g} \mathrm{~kg}^{-1}$ & ------------ & $\mathrm{mmol}_{\mathrm{c}} \mathrm{dm}^{-3}$ & ------------ & $\%$ & $\mathrm{~kg} \mathrm{dm}^{-3}$ \\
$0,0-0,05$ & 5,4 & 18 & 15,4 & 46 & 3,8 & 38 & 17 & 105 & 56 & 1,25 \\
$0,05-0,10$ & 5,0 & 14 & 12,8 & 55 & 2,5 & 33 & 13 & 104 & 47 & 1,30 \\
$0,10-0,20$ & 4,8 & 10 & 11,2 & 58 & 1,3 & 30 & 12 & 101 & 43 & 1,40 \\
$0,20-0,40$ & 4,6 & 6 & 10,8 & 66 & 0,6 & 26 & 9 & 102 & 35 & 1,35 \\
\hline
\end{tabular}

pH em $\mathrm{CaCl}_{2}$ 0,01 mol L-1, relação solo:solução (1:2,5). P e K extraído por Mehlich-1. Ca e Mg extraído pela solução KCl 1 mol $\mathrm{L}^{-1}$. CO: carbono orgânico, método Walkley - Black. Ds: densidade do solo, método do anel volumétrico (EMBRAPA, 1997).

A semeadura da soja (Glycine max L., cultivar CD 104), foi realizada no dia 06/10/2007, com 18 sementes $\mathrm{m}^{-1}$, em linhas espaçadas de $0,45 \mathrm{~m}$. A adubação mineral constou da aplicação de $300 \mathrm{~kg}$ $h^{-1}$ da formulação 00-20-20. A adubação orgânica foi realizada com a aplicação de $40 \mathrm{~m}^{3} \mathrm{ha}^{-1}$ de dejeto líquido de suínos. O dejeto de suínos foi coletado em lagoa de estabilização e apresentou as seguintes características físico-químicas: $3,2 \%$ de matéria seca; 2,20 $\mathrm{g} \mathrm{dm}^{-3}$ de $\mathrm{N} ; 0,76 \mathrm{~g} \mathrm{dm}^{-3}$ de P e 1,20 $\mathrm{g}$ $\mathrm{dm}^{-3}$ de K.

Após a colheita da soja, foram semeadas as culturas de cobertura e o trigo. A semeadura do trigo (Triticum aestivum L., cultivar CD 108) foi realizada em linhas espaçadas de $0,15 \mathrm{~m}$ com 350 sementes por $\mathrm{m}^{2}$. A adubação mineral constou da aplicação de $200 \mathrm{~kg} \mathrm{ha}^{-1}$ da formulação 04-2020 na semeadura, e $80 \mathrm{~kg} \mathrm{ha}^{-1}$ de $\mathrm{N}$ em cobertura, no período de afilhamento das plantas, na forma de ureia. A adubação orgânica foi realizada com a aplicação de $10 \mathrm{Mg} \mathrm{ha}^{-1}$ de cama-de-aviário. O esterco de frango de corte foi coletado em uma pilha de compostagem e apresentou as seguintes características físico-químicas: $86 \%$ de matéria seca; $16,0 \mathrm{~g} \mathrm{~kg}^{-1}$ de $\mathrm{N} ; 2,8 \mathrm{~g} \mathrm{~kg}^{-1}$ de $\mathrm{P}$ e $3,8 \mathrm{~g}$ $\mathrm{kg}^{-1}$ de K. A aveia preta (Avena strigosa Schreb, cultivar IPR 61), o nabo forrageiro (Rhaphanus sativus L., cultivar IPR 116) e a ervilhaca comum (Vicia sativa L., cultivar comum) foram semeados 
em linhas espaçadas de $0,15 \mathrm{~m}$, com $60 ; 20$ e 80 $\mathrm{kg} \mathrm{ha}^{-1}$ de sementes, respectivamente. Aos 95 dias após a emergência, fez-se a dessecação química das plantas com herbicida pós-emergente não-seletivo glyphosate (dose de $800 \mathrm{~g} \mathrm{ha}^{-1}$ i.a.), aplicado com pulverizador de barras motomecanizado, em volume de calda de $180 \mathrm{~L} \mathrm{ha}^{-1}$.

A semeadura do milho (Zea mays L., híbrido PIONEER 30F80) foi realizada no dia 28/09/2008, sobre a resíduos vegetais das culturas de inverno, em linhas espaçadas de $0,80 \mathrm{~m}$ com 5 sementes $\mathrm{m}^{-1}$. A adubação mineral constou da aplicação de 400 $\mathrm{kg} \mathrm{ha}^{-1}$ da formulação 04-20-20 na semeadura, e $100 \mathrm{~kg} \mathrm{ha}^{-1}$ de $\mathrm{N}$ em cobertura, na forma de ureia. A adubação orgânica foi realizada com a aplicação de $60 \mathrm{~m}^{3} \mathrm{ha}^{-1}$ de dejetos líquido de suínos. O dejeto de suínos apresentou as seguintes características físico-químicas: $3,4 \%$ de matéria seca; $2,6 \mathrm{~g} \mathrm{dm}^{-3}$ de N; 0,7 $\mathrm{g} \mathrm{dm}^{-3}$ de P e 1,0 $\mathrm{g} \mathrm{dm}^{-3}$ de K.

Após a colheita do milho, foram semeados o trigo e as culturas de cobertura (aveia preta, nabo forrageiro e ervilhaca comum) em seus respectivos tratamentos, da mesma forma como descrita para o ano anterior.

A produção de matéria seca das plantas de cobertura (aveia preta, nabo forrageiro e ervilhaca comum) foi determinada, em agosto de 2008 e 2009 , a partir de três amostras coletadas aleatoriamente com gabaritos de $0,50 \times 0,50 \mathrm{~m}$, e secas em estufa de circulação forçada de ar a $60 \pm 2{ }^{\circ} \mathrm{C}$ por $72 \mathrm{~h}$.

Em setembro de 2008 e de 2009, após a colheita do trigo e/ou manejo das culturas de cobertura, amostras de solo foram coletadas nas camadas de $0,0-0,05 ; 0,05-0,10 ; 0,10-0,20$ e 0,20-0,40 m de profundidade, com trado tipo caneca em cinco pontos por parcela, formando uma amostra composta representativa de cada tratamento. Após a coleta, as amostras foram secas ao ar, destorroadas, passadas em peneiras com malha de $2 \mathrm{~mm}$ e submetidas a determinação do teor de carbono orgânico total pelo método Walkley-Black (LANA et al., 2010). $\mathrm{O}$ estoque de carbono orgânico $\left(\mathrm{E}_{\mathrm{CO}}\right)$ foi calculado pela seguinte equação:

$$
E_{C O}=C \times D s \times \text { e } 10
$$

em que, $E_{C O}=$ estoque de carbono orgânico $(\mathrm{Mg}$ $\left.\mathrm{ha}^{-1}\right) ; C=$ teor de carbono na camada $\left(\mathrm{g} \mathrm{kg}^{-1}\right) ; D s$ $=$ densidade do solo na camada $\left(\mathrm{kg} \mathrm{dm}^{-3}\right) \mathrm{e}, e=$ espessura da camada em análise (m).

Os dados foram submetidos à análise de variância, aplicando-se o teste $\mathrm{F}$ por meio do programa estatístico SISVAR, versão 5.1 (FERREIRA, 2008). Para cada profundidade, quando significativas, as médias dos sistemas de culturas foram comparadas pelo teste de Tukey, e das fontes de nutrientes foram comparadas pelo $\mathrm{F}$, ambos a $5 \%$ de probabilidade.

\section{Resultados e Discussão}

Produtividade de matéria seca e de grãos das culturas

As plantas de cobertura apresentaram capacidade distinta de produção de matéria seca na região Oeste do Estado do Paraná (Tabela 2). A maior produção de matéria seca (MS) foi obtida com os cultivos de aveia preta (Avena strigosa Schreb) e nabo forrageiro (Rhaphanus sativus L.). A produção de MS obtida, neste estudo, encontra-se dentro do préestabelecido por Calegari (2006), que demonstrou que a aveia preta, o nabo forrageiro e a ervilhaca comum possuem, respectivamente, capacidade de produção de MS de 2.000 a 11.000 , de 3.000 a 9.000 e de 3.000 a $5.000 \mathrm{~kg} \mathrm{ha}^{-1}$. Esta elevada produção de MS das culturas de cobertura, principalmente da aveia preta e do nabo forrageiro, torna-se de extrema importância para a melhoria da qualidade do solo no sistema de plantio direto, principalmente por contribuir na redução das perdas de solo e de C orgânico (SCHICK et al., 2000; SANTOS et al., 2007), além da melhoria da estrutura dos agregados do solo (SIX et al., 2004; CALEGARI et al., 2006).

As fontes de nutrientes não influenciaram significativamente a produtividade de grãos de trigo e de milho (Tabela 2), evidenciando-se que a aplicação de esterco animal (adubação orgânica) supriu plenamente a necessidade nutricional das 
culturas, uma vez que a produtividade de grãos foi semelhante à da adubação mineral recomendada para a cultura. Tais resultados corroboram os obtidos por Matsi, Lithourgidis e Gagianas (2003), os quais verificaram que a produtividade de trigo, com a aplicação de $40 \mathrm{~m}^{3} \mathrm{ha}^{-1}$ de esterco líquido bovino, foi equivalente à da adubação mineral, nos quatro anos de avaliação. Pauletti et al. (2008) também verificaram que a aplicação de $60 \mathrm{~m}^{3} \mathrm{ha}^{-1}$ de dejeto bovino proporcionou produtividade de trigo semelhante à da adubação mineral recomendada. De modo similar, Castoldi et al. (2011) verificaram que a aplicação de esterco de aves, de forma isolada ou combinada com fertilizante mineral, não afetou significativamente a produtividade da cultura de milho.

Tabela 2. Produção de matéria seca das culturas de cobertura e produtividade de grãos de trigo e milho, afetado por sistemas de culturas e fontes de nutrientes.

\begin{tabular}{|c|c|c|c|c|c|}
\hline \multirow{2}{*}{ Fonte de variação } & \multicolumn{2}{|c|}{ Matéria seca $\left(\mathrm{kg} \mathrm{ha}^{-1}\right)^{(1)}$} & \multicolumn{3}{|c|}{ Produtividade de grãos $\left(\mathrm{kg} \mathrm{ha}^{-1}\right)$} \\
\hline & Inverno/2008 & Inverno/2009 & Trigo (2008) & Milho $(2008 / 09)$ & Trigo (2009) \\
\hline \multicolumn{6}{|l|}{ Fonte de nutrientes } \\
\hline Mineral & - & - & 1.394 & 7.387 & 2.040 \\
\hline Orgânica & - & - & 1.444 & 7.642 & 2.178 \\
\hline DMS & - & - & 156 & 816 & 224 \\
\hline \multicolumn{6}{|l|}{ Sistemas de culturas } \\
\hline $\mathrm{So} / \mathrm{Tr} / \mathrm{Mi} / \mathrm{Tr}$ & - & - & - & $6.642 \mathrm{~b}$ & - \\
\hline $\mathrm{So} / \mathrm{Av} / \mathrm{Mi} / \mathrm{Av}$ & $5.262 \mathrm{a}$ & $6.534 \mathrm{a}$ & - & $6.965 \mathrm{~b}$ & - \\
\hline $\mathrm{So} / \mathrm{Na} / \mathrm{Mi} / \mathrm{Na}$ & $4.730 \mathrm{a}$ & $5.681 \mathrm{~b}$ & - & $7.943 \mathrm{a}$ & - \\
\hline $\mathrm{So} / \mathrm{Er} / \mathrm{Mi} / \mathrm{Er}$ & $3.138 \mathrm{~b}$ & $4.028 \mathrm{c}$ & - & $8.512 \mathrm{a}$ & - \\
\hline DMS & 787 & 838 & - & 972 & - \\
\hline
\end{tabular}

So: soja, Tr: trigo, Av: aveia-preta, Na: nabo forrageiro, Er: Ervilhaca comum, Mi: milho. ${ }^{(1)}$ Produção de matéria seca das plantas de cobertura. So/Av/Mi/Av mostram a matéria seca de aveia preta. So/Na/Mi/Na mostram a matéria seca de nabo forrageiro. So/Er/ $\mathrm{Mi} /$ Er mostram a matéria seca de ervilhaca comum. Médias seguidas da mesma letra, na coluna, não diferem estatisticamente entre si pelo teste Tukey (5\%). DMS: diferença mínima significativa.

Fonte: Elaboração dos autores.

A produtividade de milho foi afetada pelos sistemas de sucessão de culturas (Tabela 2). A maior produtividade de grãos foi obtida quando o milho foi cultivado em sucessão ao nabo forrageiro e ervilhaca comum, e pode ser atribuída a maior disponibilidade de $\mathrm{N}$ no solo, em decorrência da baixa relação carbono/nitrogênio $(\mathrm{C} / \mathrm{N})$ dos resíduos vegetais destas plantas de cobertura. De acordo com Mai et al. (2003), a utilização de leguminosas e/ou nabo forrageiro como culturas de cobertura, devido a menor relação $\mathrm{C} / \mathrm{N}$ dos resíduos, pode ocasionar maior oferta de $\mathrm{N}$ no início do desenvolvimento da cultura em sucessão, resultando no aumento de produtividade. A relação $\mathrm{C} / \mathrm{N}$ dos resíduos de ervilhaca comum, nabo forrageiro e de aveia preta, em média, situa-se em torno de $13: 1,22: 1$ e $35: 1$, respectivamente (GIACOMINI et al., 2003). Por sua vez, a menor produtividade de grãos de milho em sucessão a aveia preta pode ser atribuída à maior imobilização do $\mathrm{N}$ pela biomassa microbiana do solo durante a decomposição dos resíduos vegetais de aveia, decorrente da alta relação $\mathrm{C} / \mathrm{N}$ do material vegetal deixado na superfície do solo. A presença de resíduos vegetais com alta relação $\mathrm{C} / \mathrm{N}$, normalmente superior a 30:1, tem sido uma das principais causas do menor produtividade das culturas em sucessão (AITA et al., 2001; ROSOLEM; PACE; CRUSCIOL, 2004; COSTA et al., 2011b), principalmente em decorrência da imobilização, ao menos temporária, do $\mathrm{N}$ no solo. A relação $\mathrm{C} / \mathrm{N}$ das culturas de cobertura influi na taxa de mineralização dos resíduos e, consequentemente, 
na liberação de $\mathrm{N}$ ao sistema (NICOLARDOT; RECOUS; MARY, 2001), sendo a mineralização inversamente proporcional ao teor de lignina e à relação $\mathrm{C} / \mathrm{N}$ dos resíduos, ou seja, quanto maior a relação $\mathrm{C} / \mathrm{N}$, mais lenta será a mineralização dos resíduos (AMADO; SANTI; ACOSTA, 2003). Assim, no planejamento das espécies a serem utilizadas no sistema de culturas, deve-se dar preferência a espécies leguminosas, quando se pretende implantar a cultura do milho no verão.

Resultados semelhantes foram obtidos por Aita et al. (2001) que, avaliando diferentes plantas de cobertura do solo no inverno, verificaram menor produtividade do milho em sucessão a aveia preta, quando comparada com a sucessão às leguminosas ervilhaca comum, ervilha forrageira, chícharo e tremoço azul. Aita, Port e Giacomini (2006) verificaram que no cultivo de milho em sucessão ao consórcio de aveia preta + ervilhaca comum houve uma economia de 50\% na quantidade de dejetos de suínos necessária para atingir a máxima produtividade de grãos em comparação ao cultivo de milho em sucessão a aveia preta. Tal inferência confirma a afirmação de Bortolini, Silva e Argenta (2000) de que a utilização de ervilhaca comum em cultivo isolado ou em consórcio com aveia preta diminui a necessidade de adubação nitrogenada, para o cultivo do milho em sucessão.

\section{Teor e estoque de carbono orgânico no solo}

Os teores de C orgânico do solo, nos dois anos de avaliação, são apresentados na Tabela 3. Em relação à distribuição em profundidade, o maior teor de $\mathrm{C}$ orgânico foi encontrado na camada superficial de 0,0-0,05 m, e corroborando os resultados obtidos por D’Andréa et al. (2004), Calegari et al. (2006), Pillon et al. (2007) e Pereira et al. (2010) em diferentes condições climáticas e solos brasileiros. Com a ausência de revolvimento do solo no sistema de plantio direto, aliada ao acúmulo de resíduos vegetais na superfície, ocorre maior acúmulo de $\mathrm{C}$ orgânico na camada superficial do solo (BAYER et al., 2002).

Os sistemas de sucessão de culturas não afetaram o teor de C orgânico do solo (Tabela 3), nos dois anos de avaliação. Estes resultados evidenciam que, apesar da elevada produção de material vegetal nos sistemas em sucessão com culturas de cobertura (Tabela 2), o teor de C orgânico foi pouco modificado em curto prazo. Isso pode ser atribuído ao curto período de avaliação (dois anos), o qual é considerado ainda um período de adaptação e estabelecimento dos sistemas de culturas (PILLON et al., 2007), não sendo suficiente para que as diferenças entre os sistemas se acentuassem. Em estudo conduzido durante três anos na região Oeste do Paraná, Calegari et al. (2006) também não encontraram diferenças significativas no teor de $\mathrm{C}$ orgânico no sistema de plantio direto com e sem o uso de plantas de cobertura e rotação de culturas. Entretanto, em experimento de longa duração (18 anos) conduzido no Rio Grande do Sul, Costa et al. (2008) verificaram que o plantio direto associado a sistemas de cultura com alta adição de resíduos vegetais ricos em $\mathrm{C}$ e $\mathrm{N}$ resultou no aumento do estoque de $\mathrm{C}$ orgânico no solo.

Além disso, o pouco efeito dos sistemas de culturas em sucessão com plantas de cobertura no acúmulo de $\mathrm{C}$ orgânico no solo pode ser atribuído à rápida mineralização dos resíduos vegetais em condições subtropicais, com verão quente e úmido, com é o caso da região Oeste do Paraná (Figura 1). Maria e Castro (1993) estudando a influência de sistemas de preparo do solo, de sucessão e de rotação de culturas em um Latossolo Roxo, em Campinas (SP), não observaram diferenças significativas nos teores de C orgânico na camada de 0,0-0,20 m, e atribuíram esse fato às condições climáticas da região, com verão quente e úmido e inverno seco, além do efeito da temperatura, condições estas que favorecem a rápida mineralização da matéria orgânica do solo. 
Tabela 3. Teor de carbono orgânico $\left(\mathrm{g} \mathrm{kg}^{-1}\right)$ nas camadas de $0,0-0,05 ; 0,05-0,10 ; 0,10-0,20$ e 0,20-0,40 m de solo, afetado por sistemas de culturas e fontes de nutrientes.

\begin{tabular}{|c|c|c|c|c|}
\hline \multirow{2}{*}{ Fonte de variação } & \multicolumn{4}{|c|}{ Profundidade $(\mathrm{m})$} \\
\hline & $0,0-0,05$ & $0,05-0,10$ & $0,10-0,20$ & $0,20-0,40$ \\
\hline & \multicolumn{4}{|c|}{$1^{\circ}$ ano (Safra 2007/08) } \\
\hline \multicolumn{5}{|l|}{ Fonte de nutrientes } \\
\hline Mineral & 14,6 & 12,9 & 11,1 & 11,0 \\
\hline Orgânica & 14,8 & 13,0 & 11,7 & 11,4 \\
\hline DMS & 1,6 & 1,2 & 1,0 & 1,1 \\
\hline \multicolumn{5}{|l|}{ Sistemas de culturas } \\
\hline $\mathrm{So} / \mathrm{Tr} / \mathrm{Mi} / \mathrm{Tr}$ & 14,4 & 12,5 & 11,2 & 10,4 \\
\hline $\mathrm{So} / \mathrm{Av} / \mathrm{Mi} / \mathrm{Av}$ & 14,7 & 13,0 & 11,4 & 11,2 \\
\hline $\mathrm{So} / \mathrm{Na} / \mathrm{Mi} / \mathrm{Na}$ & 14,6 & 12,8 & 11,5 & 11,6 \\
\hline $\mathrm{So} / \mathrm{Er} / \mathrm{Mi} / \mathrm{Er}$ & 15,1 & 13,6 & 11,6 & 11,6 \\
\hline DMS & 1,8 & 1,4 & 1,2 & 2,2 \\
\hline & \multicolumn{4}{|c|}{$2^{\circ}$ ano (Safra 2008/09) } \\
\hline Fonte de nutrientes & & & & \\
\hline Mineral & $14,4 \mathrm{~b}$ & 13,2 & 11,2 & 10,8 \\
\hline Orgânica & $16,4 \mathrm{a}$ & 14,1 & 11,8 & 11,3 \\
\hline DMS & 1,5 & 1,2 & 0,8 & 1,8 \\
\hline \multicolumn{5}{|l|}{ Sistemas de culturas } \\
\hline $\mathrm{So} / \mathrm{Tr} / \mathrm{Mi} / \mathrm{Tr}$ & 14,9 & 13,4 & 11,5 & 10,6 \\
\hline $\mathrm{So} / \mathrm{Av} / \mathrm{Mi} / \mathrm{Av}$ & 15,4 & 13,7 & 11,4 & 10,9 \\
\hline $\mathrm{So} / \mathrm{Na} / \mathrm{Mi} / \mathrm{Na}$ & 15,3 & 13,6 & 11,5 & 11,1 \\
\hline $\mathrm{So} / \mathrm{Er} / \mathrm{Mi} / \mathrm{Er}$ & 15,9 & 14,0 & 11,6 & 11,3 \\
\hline DMS & 1,5 & 1,3 & 1,0 & 2,1 \\
\hline
\end{tabular}

So: soja, Tr: trigo, Av: aveia-preta, Na: nabo forrageiro, Er: Ervilhaca comum, Mi: milho. Médias seguidas da mesma letra, na coluna, não diferem estatisticamente entre si pelo teste Tukey (5\%). DMS: diferença mínima significativa.

Fonte: Elaboração dos autores.

As fontes de nutrientes influenciaram vegetais e a aplicação de compostos orgânicos, e significativamente o teor de C orgânico do solo no as saídas, por meio da oxidação e decomposição da segundo ano de avaliação (Tabela 3). A aplicação de esterco animal (fonte orgânica) proporcionou aumento significativo no teor de $\mathrm{C}$ orgânico na camada de 0,0-0,05 m quando comparada à adubação mineral. De modo similar, Marchi et al. (2008) obtiveram aumentos no teor de C orgânico em um Cambissolo adubado com esterco de aves. $\mathrm{O}$ conteúdo de $\mathrm{C}$ orgânico no solo é determinado pelo balanço das entradas, como o aporte de resíduos

matéria orgânica do solo (LEITE et al., 2003).

O estoque de C orgânico no solo não foi alterado pelos sistemas de culturas e fontes de nutrientes (Tabela 4), na avaliação realizada no segundo ano de experimento. $\mathrm{O}$ estoque de $\mathrm{C}$ orgânico no solo com a adubação mineral e orgânica foi de 33,3 e 35,9 $\mathrm{Mg} \mathrm{ha}^{-1}$ na camada de 0,0-0,20 m, e de 29,2 e 30,5 $\mathrm{Mg} \mathrm{ha}^{-1}$ na camada de $0,20-0,40 \mathrm{~m}$, respectivamente (Tabela 4). 
Tabela 4. Estoque de carbono orgânico nas camadas de 0,0-0,20 e 0,20-0,40 m de solo em setembro de 2007 (início do experimento) e em setembro de 2009 ( 2 anos após) e sua variação durante o experimento, afetado por sistemas de culturas e fontes de nutrientes.

\begin{tabular}{|c|c|c|c|c|}
\hline \multirow{2}{*}{ Fonte de variação } & \multicolumn{2}{|c|}{ Estoque } & \multirow{2}{*}{\multicolumn{2}{|c|}{ Variação no período ${ }^{(1)}$}} \\
\hline & 2007 & 2009 & & \\
\hline & \multicolumn{3}{|c|}{ 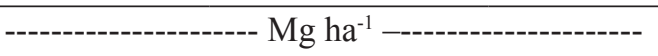 } & $\mathrm{Mg} \mathrm{ha}^{-1} \mathrm{ano}^{-1}$ \\
\hline & \multicolumn{3}{|c|}{$0,0-0,20 \mathrm{~m}$} & \\
\hline \multicolumn{5}{|l|}{ Fonte de nutrientes } \\
\hline Mineral & 33,6 & 33,3 & $-0,3$ & $-0,15$ \\
\hline Orgânica & 33,6 & 35,9 & 2,3 & 1,15 \\
\hline DMS & - & 3,1 & & \\
\hline \multicolumn{5}{|l|}{ Sistemas de culturas } \\
\hline $\mathrm{So} / \operatorname{Tr} / \mathrm{Mi} / \operatorname{Tr}$ & 33,6 & 34,1 & 0,5 & 0,25 \\
\hline $\mathrm{So} / \mathrm{Av} / \mathrm{Mi} / \mathrm{Av}$ & 33,6 & 34,5 & 0,9 & 0,45 \\
\hline $\mathrm{So} / \mathrm{Na} / \mathrm{Mi} / \mathrm{Na}$ & 33,6 & 34,5 & 0,9 & 0,45 \\
\hline $\mathrm{So} / \mathrm{Er} / \mathrm{Mi} / \mathrm{Er}$ & 33,6 & 35,3 & 1,7 & 0,85 \\
\hline \multirow[t]{2}{*}{ DMS } & - & 2,9 & & \\
\hline & \multicolumn{4}{|c|}{$0,20-0,40 \mathrm{~m}$} \\
\hline \multicolumn{5}{|l|}{ Fonte de nutrientes } \\
\hline Mineral & 29,2 & 29,2 & 0,0 & 0,00 \\
\hline Orgânica & 29,2 & 30,5 & 1,3 & 0,65 \\
\hline DMS & & 2,6 & & \\
\hline \multicolumn{5}{|l|}{ Sistemas de culturas } \\
\hline $\mathrm{So} / \mathrm{Tr} / \mathrm{Mi} / \mathrm{Tr}$ & 29,2 & 28,6 & $-0,6$ & $-0,30$ \\
\hline $\mathrm{So} / \mathrm{Av} / \mathrm{Mi} / \mathrm{Av}$ & 29,2 & 29,4 & 0,2 & 0,10 \\
\hline $\mathrm{So} / \mathrm{Na} / \mathrm{Mi} / \mathrm{Na}$ & 29,2 & 30,0 & 0,8 & 0,40 \\
\hline $\mathrm{So} / \mathrm{Er} / \mathrm{Mi} / \mathrm{Er}$ & 29,2 & 30,5 & 1,3 & 0,65 \\
\hline DMS & & 2,8 & & \\
\hline
\end{tabular}

So: soja, Tr: trigo, Av: aveia-preta, Na: nabo forrageiro, Er: Ervilhaca comum, Mi: milho. DMS: diferença mínima significativa. ${ }^{(1)}$ Sinais negativo e positivo significam emissão e retenção líquida de C no sistema solo-atmosfera, respectivamente.

Fonte: Elaboração dos autores.

Os estoques de $\mathrm{C}$ orgânico, na camada de 0,0-0,20 m, nos diferentes sistemas de culturas variaram de 34,1 a $35,3 \mathrm{Mg} \mathrm{ha}^{-1}$, respectivamente, nos sistemas soja/trigo/milho/trigo e soja/ervilhaca/ milho/ervilhaca (Tabela 4). Em experimento conduzido em Uberaba (MG), em um Latossolo Vermelho sob plantio direto, Pereira et al. (2010) também não encontraram efeitos significativos do uso de braquiária (Brachiaria brizantha), milheto (Pennisetum americanum) e crotalária (Crotalaria juncea) como planta de cobertura do solo no estoque de carbono orgânico na camada de 0,0-0,20 m em comparação ao pousio.
$\mathrm{O}$ estoque de $\mathrm{C}$ orgânico do solo pode ser alterado com maior ou menor intensidade, dependendo do sistema agrícola instalado, sendo um dos atributos mais sensíveis a transformações desencadeadas pelo manejo. Práticas de manejo inadequadas podem levar a um rápido declínio destes estoques, contribuindo para o aumento das emissões de dióxido de carbono $\left(\mathrm{CO}_{2}\right)$ à atmosfera (FREIXO et al., 2002). A adubação mineral, no presente trabalho, resultou em um saldo negativo no estoque de $C$ orgânico na camada $0,0-0,20 \mathrm{~m}$ de solo (Tabela 4). O estoque de $\mathrm{C}$ que, inicialmente, era de $33,6 \mathrm{Mg} \mathrm{ha}^{-1}$ passou para $33,3 \mathrm{Mg} \mathrm{ha}^{-1}$ ao final do segundo ano, representando uma redução no 
estoque de C orgânico de $0,15 \mathrm{Mg} \mathrm{ha}^{-1}$ ano $^{-1}$ (Tabela 4). $\mathrm{Na}$ camada de $0,20-0,40 \mathrm{~m}$ de profundidade $\mathrm{o}$ estoque de $\mathrm{C}$ orgânico permaneceu inalterado nos dois anos de avaliação.

Os resultados de estoque de carbono encontrados neste estudo são considerados altos se comparados com outros trabalhos da literatura (CONCEIÇÃO et al., 2005; CANELLAS et al., 2007; BLANCHART et al., 2007; PEREIRA et al., 2010). O acúmulo de $\mathrm{C}$ pode variar regionalmente devido às condições climáticas (CARVALHO et al., 2010), ao tipo de solo (BAYER; MIELNICZUK, 1999), ao manejo aplicado e, principalmente, em função do tempo de implantação do sistema de plantio direto (CARVALHO et al., 2009). Estudos de longa duração realizados em sistema de plantio direto no Sul do Brasil indicam taxas anuais potenciais de acúmulo de $\mathrm{C}$ orgânico no solo variando entre 0,5 a 1,0 $\mathrm{Mg} \mathrm{ha}^{-1}$, para intervalos entre 0 e 16 anos (PILLON et al., 2007).

$\mathrm{O}$ aporte anual de $\mathrm{C}$ orgânico, na camada de 0,0-0,20 m, foi positivo em todos os sistemas de sucessão de culturas (Tabela 4), entretanto, houve variação entre os sistemas estudados. O maior aporte de $\mathrm{C}$ no solo foi verificado no sistema soja/ ervilhaca/milho/ervilhaca com $0,85 \mathrm{Mg} \mathrm{ha}^{-1}$ ano $^{-1}$, e pode ser atribuído a maior disponibilidade de $\mathrm{N}$ no sistema, em decorrência da fixação biológicas do $\mathrm{N}_{2}$ atmosférico pelas plantas de ervilhaca comum. Segundo Souza et al. (2009), aumentos no estoque de C orgânico no solo estão relacionados a aumentos na disponibilidade de $\mathrm{N}$ no sistema soloplanta. Por sua vez, o menor aporte de C no solo $\left(0,25 \mathrm{Mg} \mathrm{ha}^{-1}\right.$ ano $\left.^{-1}\right)$ no sistema soja/trigo/milho/ trigo, ocorreu devido a menor adição de resíduos vegetais ao solo. Já, na camada de 0,20-0,40 m este sistema proporcionou um saldo negativo de $\mathrm{C}$ no solo (Tabela 4).

Em experimento de longa duração (18 anos) conduzido no Rio Grande do Sul, Costa et al. (2008) verificaram, no sistema de plantio direto, que o sistema de cultura ervilhaca/milho apresentou aporte líquido de $\mathrm{C}$ no solo de $0,15 \mathrm{Mg} \mathrm{ha}^{-1}$ ano $^{-}$ 1. Os autores atribuíram estes resultados à maior adição de resíduos ao solo, principalmente pela cultura do milho em sucessão. Na sucessão aveia preta/milho, em que a adição de resíduos vegetais foi menor, o balanço de $\mathrm{C}$ no solo foi negativo, indicando que o solo atuou como fonte de $\mathrm{C}-\mathrm{CO}_{2}$ para a atmosfera numa taxa de $0,12 \mathrm{Mg} \mathrm{ha}^{-1} \mathrm{ano}^{-1}$. Em um Argissolo de ambiente subtropical, Lovato et al. (2004) constataram que no sistema de plantio direto há necessidade de uma adição anual de cerca de $10,0 \mathrm{Mg} \mathrm{ha}^{-1}$ de resíduos vegetais (45\% de C, $\mathrm{m}: \mathrm{m})$ para manter o estoque inicial de $\mathrm{C}$ orgânico do solo. Em outro experimento, conduzido no Rio Grande do Sul, Zanatta et al. (2007) evidenciaram a necessidade de 13,0 $\mathrm{Mg} \mathrm{ha}^{-1}$ de matéria seca no sistema de plantio direto, para manter o estoque inicial de $\mathrm{C}$ no solo. Estes dados demonstram a importância do alto aporte de resíduos vegetais no solo quando se visa ao acúmulo de $\mathrm{C}$ orgânico no solo, similarmente ao que já foi observado por Lovato et al. (2004) e Bayer et al. (2006). Nesse sentido, Amado et al. (2001) verificaram que o uso de leguminosas, combinado com uma maior diversidade de espécies em sucessão ou rotação de culturas, aumentou a retenção de C e N no solo, com implicações importantes para o balanço destes elementos em escala regional e global e para a produção sustentável e a qualidade ambiental. Esses autores destacaram ainda que, além de melhorar a qualidade do solo, o uso de leguminosas resulta em menor custo financeiro e energético da produção de grãos, pelo suprimento parcial do $\mathrm{N}$ e redução da necessidade de fertilizantes nitrogenados.

\section{Conclusões}

Os diferentes sistemas de sucessão de culturas não afetaram os teores e os estoques de carbono orgânico do solo nos dois primeiros anos de adoção dos sistemas.

A adubação orgânica com esterco animal proporcionou aumento nos teores de carbono orgânico do solo. 
Sistemas de culturas adubados com fertilizante mineral proporcionam as maiores perdas de carbono orgânico no solo, resultando em balanço negativo de C no solo.

\section{Referências}

AITA, C.; BASSO, C. J.; CERETTA, C. A.; GONÇALVES, C. N.; DA ROS, C. O. C. Plantas de cobertura de solo como fontes de nitrogênio ao milho. Revista Brasileira de Ciência do Solo, Viçosa, v. 25, n. 1, p. 157-165, 2001.

AITA, C.; PORT, O.; GIACOMINI, S. J. Dinâmica do nitrogênio no solo e produção de fitomassa por plantas de cobertura no outono/inverno com o uso de dejetos de suínos. Revista Brasileira de Ciência do Solo, Viçosa, v. 30, n. 5, p. 901-910, 2006.

AMADO, T. J. C.; BAYER, C.; ELTZ, F. L. F.; BRUM, A. C. R. Potencial de culturas de cobertura em acumular carbono e nitrogênio no solo no plantio direto e a melhoria da qualidade ambiental. Revista Brasileira de Ciência do Solo, Viçosa, v. 25, n. 1, p. 189-197, 2001.

AMADO, T. J. C.; SANTI, A.; ACOSTA, J. A. A. Adubação nitrogenada na aveia preta. II - Influência na decomposição de resíduos, liberação de nitrogênio e rendimento de milho sob sistema plantio direto. Revista Brasileira de Ciência do Solo, Viçosa, v. 27, n. 6, p. 1085-1096, 2003.

ANDREOLA, F.; COSTA, L. M.; MENDONÇA, E. S.; OLSZEVSKI, N. Propriedades químicas de uma Terra Roxa Estruturada influenciadas pela cobertura vegetal de inverno e pela adubação orgânica e mineral. Revista Brasileira de Ciência do Solo, Viçosa, v. 24, n. 3, p. 609620, 2000.

BAYER, C.; MIELNICZUK, J.; MARTIN-NETO, L.; ERNANI, P. R. Stocks and humification degree of organic matter fractions as affected by no-tillage on a subtropical soil. Plant and Soil, Dordrechet, v. 238, n. 1, p. 133-140, 2002.

BAYER, C.; MARTIN-NETO, L.; MIELNICZUK, J.; PAVINATO, A.; DIECKOW, J. Carbon sequestration in two Brazilian Cerrado soils under no-till. Soil \& Tillage Research, Amsterdam, v. 86, n. 2, p. 237-245, 2006.

BAYER, C.; MIELNICZUK, J. Dinâmica e função da matéria orgânica. In: SANTOS, G. A.; CAMARGO, F. A. O. (Ed.). Matéria orgânica do solo: fundamentos e caracterização. Porto Alegre: Gênesis, 1999. p. 9-16.

BLANCHART, E.; BERNOUX, M.; SARDA, X.; SIQUEIRA NETO, M.; CERRI, C. C.; PICCOLO, M.
C.; DOUZET, J. M.; SCOPEL, E.; FELLER, C. Effect of direct seeding mulch-based systems on soil carbon storage and macrofauna in Central Brazil. Agriculturae Conspectus Scientificus, Zagreb, v. 72, n. 1, p. 81-87, 2007.

BORTOLINI, C. G.; SILVA, P. R. F.; ARGENTA, G. Sistemas consorciados de aveia preta e ervilhaca comum como cobertura de solo e seus efeitos na cultura do milho em sucessão. Revista Brasileira de Ciência do Solo, Viçosa, v. 24, n. 4, p. 897-903, 2000.

CALEGARI, A. Plantas de cobertura. In: CASÃO JUNIOR, R.; SIQUEIRA, R.; MEHTA, Y. R.; PASSINI, J. J. (Ed.). Sistema plantio direto com qualidade. Londrina: IAPAR; Foz do Iguaçu: ITAIPU BINACIONAL, 2006. cap. 5, p. 55-74.

CALEGARI, A.; CASTRO FILHO, C. de; TAVARES FILHO, J.; RALISCH, R.; GUIMARÃES, M. F. Melhoria da agregação do solo através do sistema plantio direto. Semina: Ciências Agrárias, Londrina, v. 27, n. 2, p. 147-158, 2006.

CANELLAS, L. P.; BALDOTTO, M. A.; BUSATO, J. G.; MARCIANO, C. R.; MENEZES, S. C.; SILVA, N. M.; RUMJANEK, V. M.; VELLOSO, A. C. X.; SIMÕES, M. L.; MARTIN-NETO, L. Estoque e qualidade da matéria orgânica de um solo cultivado com cana-de-açúcar por longo tempo. Revista Brasileira de Ciência do Solo, Viçosa, v. 31, n. 2, p. 331-340, 2007.

CARNEIRO, C. E. A.; MELÉM JÚNIOR, N. J.; AZEVEDO, M. C. B. de; ANDRADE, E. A.; KOGUISHI, M. S.; DIEHL, R. C.; RICCE, W. S.; PASSARIN, A. L.; VAZ, R. H. M.; STELMACHUK, T. L. L.; GUIMARÃES, M. F.; RALISCH, R. Efeitos dos sistemas de manejo sobre o carbono orgânico total e carbono residual de um Latossolo vermelho eutroférrico. Semina: Ciências Agrárias, Londrina, v. 30, n. 1, p. 5-10, 2009.

CARVALHO, J. L. N.; AVANZI, J. C.; SILVA, M. L. N.; MELLO, C. R.; CERRI, C. E. P. Potencial de sequestro de carbono em diferentes biomas do Brasil. Revista Brasileira de Ciência do Solo, Viçosa, v. 34, n. 2, p. 277 289, 2010.

CARVALHO, J. L. N.; CERRI, C. E. P.; FEIGL, B. J.; PICOLlO, M. C.; GODINHO, V. P.; CERRI, C. C. Carbon sequestration in agricultural soils in the Cerrado region of the Brazilian Amazon. Soil \& Tillage Research, Amsterdam, v. 103, n. 2, p. 342-349, 2009.

CASTOLDI, G.; PIVETTA, L. A.; STEINER, F.; COSTA, M. M. S. C.; COSTA, L. A. M. Sistemas de produção e sua influência na cultura do milho safrinha em plantio direto. Scientia Agraria Paranaensis, Marechal Cândido Rondon, v. 10, n. 1, p. 47-57, 2011. 
CONCEIÇÃO, P. C.; AMADO, T. J. C.; MIELNICZUK, J.; SPAGNOLLO, E. Qualidade do solo em sistemas de manejo avaliada pela dinâmica da matéria orgânica e atributos correlacionados. Revista Brasileira de Ciência do Solo, Viçosa, v. 29, n. 5, p. 777-788, 2005.

COSTA, F. S.; BAYER, C.; ZANATTA, J. A.; MIELNICZUK, J. Estoque de carbono orgânico no solo e emissões de dióxido de carbono influenciadas por sistemas de manejo no Sul do Brasil. Revista Brasileira de Ciência do Solo, Viçosa, v. 32, n. 1, p. 323-332, 2008.

COSTA, M. S. S. M.; PIVETTA, L. A.; COSTA, L. A. M.; PIVETTA, L. A.; CASTOLDI, G.; STEINER, F. Atributos físicos do solo e produtividade do milho sob sistemas de manejo e adubações. Revista Brasileira de Engenharia Agrícola e Ambiental, Campina Grande, v. 15, n. 8, p. 810-815, 2011 a.

COSTA, M. S. S. M.; STEINER, F.; COSTA, L. A. M.; CASTOLDI, G.; PIVETTA, L. A. Nutrição e produtividade da cultura do milho em sistemas de culturas e fontes de adubação. Revista Ceres, Viçosa, v. 58 , n. 2, p. 249-255, 2011 b.

D'ANDRÉA, A. F.; SILVA, M. L. N.; CURI, N.; GUILHERME, L. R. G. Estoque de carbono e nitrogênio e formas de nitrogênio mineral em um solo submetido a diferentes sistemas de manejo. Pesquisa Agropecuária Brasileira, Brasília, v. 39, n. 2, p. 179-186, 2004.

EMPRESA BRASILEIRA DE PESQUISA AGROPECUÁRIA - EMBRAPA. Manual de métodos de análise de solo. 2. ed. Rio de Janeiro: Embrapa Solos, 1997. $212 \mathrm{p}$.

FERREIRA, D. F. SISVAR: um programa para análises e ensino de estatística. Revista Cientifica Symposium, Lavras, v. 6, n. 2, p. 36-41, 2008.

FREIXO, A.A.; MACHADO, P. L. O. A.; GUIMARÃES, C. M.; SILVA, C. A.; FADIGAS, F. S. Estoques de carbono e nitrogênio e distribuição de frações orgânicas de Latossolo do Cerrado sob diferentes sistemas de cultivo. Revista Brasileira de Ciência do Solo, Viçosa, v. 26, n. 2, p. 425-434, 2002.

GIACOMINI, S. J.; AITA, C.; VENDRUSCOLO, E. R. O.; CUBILLA, M.; NICOLOSO, R. S.; FRIES, M. R. Matéria seca, relação $\mathrm{C} / \mathrm{N}$ e acúmulo de nitrogênio, fósforo e potássio em misturas de plantas de cobertura de solo. Revista Brasileira de Ciência do Solo, Viçosa, v. 27, n. 2, p. 325-334, 2003.

KONZEN, E. A.; ALVARENGA, R. C. Manejo $e$ utilização de dejetos animais: aspectos agronômicos e ambientais. Sete Lagoas: EMBRAPA, 2005. (Circular técnica, 63).
LANA, M. C.; FEY, R.; FRANDOLOSO, J. F.; RICHART, A.; FONTANIVA, S. Análise química de solo e tecido vegetal: práticas de laboratório. Cascavel: EDUNIOESTE, 2010. $130 \mathrm{p}$.

LEITE, L. F. C.; MENDONÇA, E. S.; NEVES, J. C. L.; MACHADO, P. L. O. A.; GALVÃO, J. C. C. Estoques totais de $\mathrm{C}$ orgânico e seus compartimentos em Argissolo sob floresta e sob milho cultivado com adubação mineral e orgânica. Revista Brasileira de Ciência do Solo, Viçosa, v. 27, n. 5, p. 821-832, 2003.

LOVATO, T.; MIELNICZUK, J.; BAYER, C.; VEZZANI, F. Adição de carbono e nitrogênio e sua relação com os estoques no solo e com o rendimento do milho em sistemas de manejo. Revista Brasileira de Ciência do Solo, Viçosa, v. 28, n. 1, p. 175-187, 2004.

MAI, M. E. M.; CERETTA, C. A.; BASSO, C. J.; SILVEIRA, M. J.; PAVINATO, A.; PAVINATO, O. S. Manejo da adubação nitrogenada na sucessão aveia-preta/ milho no sistema plantio direto. Pesquisa Agropecuária Brasileira, Brasília, v. 38, n. 1, p. 125-131, 2003.

MARCHI, E. C. S.; ALVARENGA, M. A. R.; MARCHI, G.; SILVA, C.A.; SOUZAFILHO, J. L. Efeito da adubação orgânica sobre as frações de carbono de solos cultivados com alface americana. Ciência e Agrotecnologia, Lavras, v. 32 , n. 6 , p. $1760-1766,2008$.

MARIA, I. C.; CASTRO, O. M. Fósforo, potássio e matéria orgânica em um Latossolo roxo sob sistemas de manejo com milho e soja. Revista Brasileira de Ciência do Solo, Campinas, v. 17, n. 3, p. 471-477, 1993.

MATSI, T.; LITHOURGIDIS, A. S.; GAGIANAS, A. A. Effects of injected liquid cattle manure on growth and yield of winter wheat and soil characteristics. Agronomy Journal, Madison, v. 95, n. 3, p. 592-596, 2003.

MOSADDEGHI, M. R.; MAHBOUBI, A. A.; SAFADOUST, A. Short-term effects of tillage and manure on some soil physical properties and maize root growth in a sandy loam soil in western Iran. Soil \& Tillage Research, Amsterdam, v. 104, n. 1, p. 173-179, 2009.

NICOLARDOT, B.; RECOUS, S.; MARY, B. Simulation of $\mathrm{C}$ and $\mathrm{N}$ mineralisation during crop residue decomposition: A simple dynamic model based on the $\mathrm{C} / \mathrm{N}$ ratio of the residues. Plant and Soil, Dordrechet, v. 228, n. 1, p. 83-103, 2001.

PAUletTI, V.; BARCELlOS, M.; MOTTA, A. C. V.; SERRAT, B. M.; SANTOS, I. R. Produtividade de culturas sob diferentes doses de esterco líquido de gado de leite e de adubo mineral. Scientia Agrária, Curitiba, v. 9, n. 2, p. 199-205, 2008. 
PEREIRA, M. G.; LOSS, A.; BEUTLER, S. J.; TORRES, J. L. R. Carbono, matéria orgânica leve e fósforo remanescente em diferentes sistemas de manejo do solo. Pesquisa Agropecuária Brasileira, Brasília, v. 45, n. 5, p. 508-514, 2010.

PILLON, C. N.; SCIVITTARO, W. B.; POTES, M. L. P.; MORAES, C. S.; MICHELS, G. H.; PEREIRA, J. S. Acúmulo de carbono orgânico por sistemas de cultura sob plantio direto em terras baixas. Revista Brasileira de Agroecologia, Curitiba, v. 2, n. 1, p. 1040-1043, 2007.

RAIJ, B. van; CANTARELlA, H.; QUAGGIO, J. A.; FURLANI, A. M. C. Recomendações de adubação e calagem para o Estado de São Paulo. 2. ed. Campinas: Instituto Agronômico, 1997. 285 p. (Boletim técnico, $100)$.

ROSOlEM, C. A.; PACE, L.; CRUSCIOL, C. A. C. Nitrogen management in maize cover crop rotations. Plant and Soil, Dordrechet, v. 264, n. 1-2, p. 261-271, 2004.

SANTOS, T. E. M.; MONTENEGRO, A. A. A.; SILVA, Ê. F. F.; LIMA NETO, J. A. Perdas de carbono orgânico, potássio e solo em Neossolo Flúvico sob diferentes sistemas de manejo no semi-árido. Revista Brasileira de Ciências Agrárias, Recife, v. 2, n. 2, p. 143-149, 2007.

SCHERER, E. E.; NESI, C. N. Características químicas de um Latossolo sob diferentes sistemas de preparo e adubação orgânica. Bragantia, Campinas, v. 68, n. 3, p. 715-721, 2009.
SCHICK, J.; BERTOL, I.; BALBINOT JUNIOR, A. A.; BATISTELA, O. Erosão hídrica em Cambissolo Húmico alumínico submetido a diferentes sistemas de preparo e cultivo do solo: II. Perdas de nutrientes e carbono orgânico. Revista Brasileira de Ciência do Solo, Viçosa, v. 24, n. 2, p. 437-447, 2000.

SIX, J.; OGLE, S. M.; BREIDT, F. J.; CONANT, R. T.; MOSIER, A. R.; PAUSTIAN, K. The potential to mitigate global warming with no-tillage management is only realized when practiced in the long term. Global Change Biology, Urbana, v. 10, n. 2, p. 155-160, 2004.

SOUZA, E. D.; COSTA, S. E. V. G. A.; ANGHINONI, I.; CARVALHO, P. C. F.; ANDRIGUETI, M.; CAO, E. Estoques de carbono orgânico e de nitrogênio no solo em sistema de integração lavoura-pecuária em plantio direto, submetido a intensidades de pastejo. Revista Brasileira de Ciência do Solo, Viçosa, v. 33, n. 6, p. 1829-1836, 2009.

ZANATTA, J. A.; BAYER, C.; DIECKOW, J.; VIEIRA, F. C. B.; MIELNICZUK, J. Soil organic carbon accumulation and carbon costs related to tillage, cropping systems and nitrogen fertilization in a subtropical Acrisol. Soil \& Tillage Research, Amsterdam, v. 94, n. 2, p. 510519, 2007. 
